\title{
REFLEXÕES ENTRE A PRÁTICA E A TEORIA A PARTIR DE OLHARES DE BOLSISTAS DO PIBID APLICADOS EM ESCOLAS DA REDE PÚBLICA MUNICIPAL DE PORTO ALEGRE/RS'
}

\author{
João Batista da Silva Goulart ${ }^{2}$ \\ Anie Cristine Pires Gabriel ${ }^{3}$ \\ Mariele Schutz dos Santos ${ }^{4}$ \\ Magali de Morais Menti5
}

\begin{abstract}
RESUMO: O texto apresenta elementos constituintes de três relatos de experiência do subprojeto Letras: Língua Portuguesa - Programa Institucional de Bolsas de Iniciação à Docência, da Universidade Estadual do Rio Grande do Sul (UERGS), no período de 2018 a 2019, realizados na Escola Municipal de Ensino Fundamental Timbaúva e no Centro Municipal de Educação de Trabalhadores - Paulo Freire (Ensino de Jovens e Adultos), ambas em Porto Alegre/RS. Objetiva relatar e refletir sobre as percepções vivenciadas pelos bolsistas de iniciação à docência, desde o planejamento e elaboração dos projetos até a aplicação destes em sala de aula, por meio de oficinas e vivências que visaram a educação transformadora. Deste modo, a partir da reflexão do referencial teórico utilizado e da aplicação dele no referido subprojeto, desenvolveram-se habilidades de produção textual, leitura e oralidade que capacitaram os alunos à reflexão linguística dos gêneros, a partir da percepção inclusiva e da transformação crítica e social, portanto, ressignificando suas trilhas nas escolas. Assim, o Pibid estimula professores e alunos, por intermédio da articulação e reflexão entre teoria e prática, fazendo com que as aprendizagens e experiências sejam trocas (res)significativas.

Palavras-Chave: Educação; Formação Docente; Licenciatura; PIBID.

ABSTRACT: The article presents the constituent elements of three experience reports of the Subproject Letters: Portuguese Language/Institutional Program of Teaching Initiation Scholarships - PIBID, of the State University of Rio Grande do Sul (Uergs), from 2018 to 2019, held at the Timbaúva/EMEF Municipal Elementary School and the Municipal Center for Worker Education CMET - Paulo Freire (Youth and Adult Education), both in Porto Alegre/RS. It aims to report the perceptions experienced by the students of initiation to teaching, from the planning and elaboration of the projects to the methodological application of these in the classroom, through workshops and experiences aimed at transforming education. Thus, from the reflection of the theoretical framework used and its application in the subproject, skills of textual production, reading and orality were developed, which empowered students to linguistic reflection of genders, based on the perception and critical and social transformation, therefore, remaining its trails in schools. Thus, PIBID stimulates teachers and students, through the articulation and reflection between theory and practice, causing learning and experiences are significant exchanges.
\end{abstract}

Keywords: Education; Teacher Education; Bachelor's Degree.

\footnotetext{
${ }^{1}$ Este trabalho foi produzido com apoio do Programa PIBID/Capes.

2 Licenciando em Letras Língua Portuguesa e Literaturas de Língua Portuguesa pela Universidade Estadual do Rio Grande do Sul. Bolsista ID/PIBID/CAPES. E-mail: joao-goulart@uergs.edu.br

3 Licencianda em Letras Língua Portuguesa e Literaturas de Língua Portuguesa pela Universidade Estadual do Rio Grande do Sul. Bolsista ID/PIBID/CAPES. E-mail: aniecristinep@gmail.com

${ }^{4}$ Licencianda em Letras Língua Portuguesa e Literaturas de Língua Portuguesa pela Universidade Estadual do Rio Grande do Sul. Bolsista ID/PIBID/CAPES. E-mail: marieleschutzdossantos@gmail.com

5 Professora Adjunta da Universidade Estadual do Rio Grande do Sul, Campus Central - Curso de Licenciatura em Letras Língua Portuguesa e Literaturas de Língua Portuguesa. Doutora em Letras/Linguística Aplicada pela UFRGS; Coordenadora de Núcleo/PIBID/CAPES. E-mail: magali-menti@uergs.edu.br
} 
- Revista de Iniciação à Docência, v. 5, n. 2, 2020 -

Publicação: agosto, 2020 - ISSN 2525-4332

\section{Introdução}

O Programa Institucional de Bolsas de Iniciação à Docência - PIBID (2019) tem o objetivo de proporcionar aos acadêmicos dos cursos de licenciatura o contato, na qualidade de bolsista de iniciação à docência - Bolsista ID -, mesmo antes do estágio obrigatório, com a realidade da escola pública. Nesse contexto, os futuros professores são estimulados à prática, aproximando-se da realidade da sala de aula. Assim sendo, as atividades, as orientações, os pontos de vista e as experiências de forma geral são agregadas à formação acadêmica.

Neste trabalho, serão destacados os fatos significativos que foram observados durante a realização de três projetos - duas oficinas e uma vivência - que fizeram parte do subprojeto do curso de Letras: Licenciatura em Língua Portuguesa e Literaturas de Língua Portuguesa da Universidade Estadual do Rio Grande do Sul, no biênio 2018/2019. Num contexto geral, estes projetos foram realizados a partir de uma metodologia ancorada na Pedagogia de Projetos, por meio da experiência que despertasse o interesse dos alunos e favorecesse o ensino com base nas descobertas, frutos das pesquisas realizadas por eles. O objetivo deste trabalho é relatar as percepções e as experiências vividas no grupo de estudos, na monitoria docente em sala de aula, no planejamento e na elaboração dos projetos.

Entrementes, os projetos foram aplicados em duas escolas diferentes, uma de Ensino Fundamental (EF) e outra de Educação de Jovens e Adultos (EJA), ambas pertencentes à rede municipal de Porto Alegre/RS e com características e realidades diferentes. Entretanto, os fatores socioeconômicos de seus sujeitos (alunos) eram semelhantes. Na caracterização do diagnóstico desenvolvido no EF, registraram-se as críticas às fragmentações observadas no tratamento das disciplinas - precisamente na área de Linguagens, Códigos e suas Tecnologias: Língua Portuguesa - e na interação dos alunos com a disciplina de Língua Portuguesa, vista por alguns como uma disciplina difícil e complicada - devido às inúmeras regras e convenções -, porém necessárias. Assim, a falta ou entendimento diverso de que os conhecimentos prévios dos alunos devem ser integrados à bagagem de conhecimentos do professor no planejamento de uma boa aula, aliados a uma política de "desmanche" da educação e desvalorização dos professores, são fatores que contribuem também para a desmotivação dos docentes e dos discentes, ocasionando taxas de absenteísmo, infrequência, abandono e evasão escolar.

Nesse sentido, uma vez que cada docente é responsável por ministrar sua disciplina, as demandas de planejamento de aula, não raras vezes, acabam sendo prejudicadas por questões estruturais da administração escolar, que são cambiáveis, mas não articulam as disciplinas; logo, alunos e professores acabam por exaurir conhecimento no horizonte sem fim da disciplinaridade. Assim, tanto os professores têm bagagens culturais e acadêmicas, quanto os alunos têm conhecimentos prévios que não podem ser subestimados pela falta de gerenciamento escolar ou por políticas educacionais que visam a um sistema de transmissão de saberes intrínsecos ao lucro e negam temas transversais - nos currículos - 
que façam dos alunos seres proativos na sua comunidade.

Embora a realidade escolar, mais precisamente, da Educação Básica, seja desafiadora, não obstante a EJA também jaz no desafio. Os níveis de aprendizagem dos estudantes desta modalidade sofrem de variáveis que influenciam no processo de construção do conhecimento, tais como: dificuldades de aprendizagem em virtude das diferenças etárias existentes em sala de aula, atrasos decorrentes da jornada de trabalho, reflexos da evasão escolar prematura, entre outros. Contudo, é sabido que um dos motivos do retorno de jovens e adultos à escola é a possibilidade de conseguir uma colocação melhor no mercado de trabalho.

Nesse sentido, eles frequentam a escola no período noturno para acessar outros graus de ensino e habilitações profissionais, em virtude das exigências educativas na sociedade contemporânea. Sendo assim, muitos são aqueles que, por algum motivo ocorrido no passado, desistiram de estudar e para melhorar seu currículo e formação, a fim de se prepararem para as exigências do mundo do trabalho, retornaram à sala de aula.

\section{Metodologia}

De acordo com a Coordenação de Aperfeiçoamento de Pessoal de Nível Superior CAPES (2019)-, o Pibid visa ao aperfeiçoamento e à valorização da formação de professores para a educação básica. O programa pretende elevar a qualidade da formação docente nos cursos de licenciatura das Instituições de Educação Superior (IES), inserindo os licenciandos no cotidiano escolar. Os alunos de licenciaturas são selecionados por meio de editais divulgados pelas IES e após terem sido selecionados e qualificados, recebem uma bolsa e começam suas atividades, tanto nas escolas como nas IES, de acordo com cada subprojeto aprovado, integrando teoria e "práticas docentes inovadoras e interdisciplinares que busquem a superação de problemas de ensino-aprendizagem" (BRASIL, 2018).

O subprojeto do curso de Licenciatura em Letras da Uergs tem quatro importantes finalidades: contribuir para a formação docente de discentes participantes do Pibid; ofertar oportunidades de formação continuada a professores já graduados e atuantes; desenvolver as habilidade de expressão oral e escrita de alunos da educação básica; e, aproveitar livros didáticos subutilizados e disponíveis nas escolas. Alinhado à proposta institucional para o Pibid, que procura desenvolver múltiplos letramentos e diversidade no ensino básico, foram realizadas oficinas com exercícios de letramento linguístico com base nos gêneros textuais, sequências pedagógicas fundamentadas em diversidades e variações linguísticas com uso de múltiplos letramentos.

As atividades dos projetos propostos por nosso grupo de trabalho (GT) foram definidas a cada período semestral no qual o GT era transferido para outra escola participante do subprojeto institucional de Letras. Nesse sentido, tínhamos carga horária de 32 horas mensais divididas entre o grupo de estudos, a monitoria didática, a reunião geral com a coordenação de núcleo do subprojeto e as reuniões com as supervisoras de 
núcleo da escola, a fim de que pudéssemos realizar o planejamento das atividades, pois, segundo Leal (2005), todas as ações previstas deveriam ser sistematizadas para o desenvolvimento "eficiente e eficaz" pelo grupo.

Definido o planejamento, nosso próximo passo seria a escolha de uma metodologia que estivesse alinhada ao subprojeto e, nesse contexto, a pedagogia de projetos foi a alternativa que resolvemos propor, pois queríamos que nossos alunos, oficinistas, vivencialistas e "esperancistas" fossem ávidos por uma aula, oficina, vivência ou "esperança" que ousasse em formá-los cidadãos independentes, críticos e participativos na sociedade. Desse modo, buscou-se uma prática docente que pudesse superar a possível fragmentação do saber decorrente das "caixas" de cada especialização lincadas à disciplinaridade.

Sabíamos que ao propor uma abordagem baseada em projetos, teríamos o desafio de colocar em prática uma visão interdisciplinar do conhecimento por meio de um aprendizado o qual propusesse o desenvolvimento da autonomia dos alunos, portanto, contribuindo para a transformação deles em indivíduos socialmente proativos. Assim, de acordo com Fazenda e Casadei (2012), com os componentes didáticos a serem trabalhados em sala de aula, escolhidos e dialogando entre si com as demais áreas de conhecimento e suas complexidades, sistematizamos o planejamento em um processo de mudança de atitude no compreender e entender o conhecimento, em trocas nas quais todos saem ganhando, os alunos, os professores e a instituição (FAZENDA; CASADEI, 2012).

Neste sentido, no segundo semestre do ano de 2018, iniciamos nossa oficina intitulada "Contadores de Histórias - Conte-me um Conto", realizada com alunos da Escola Municipal de Ensino Fundamental Timbaúva, em Porto Alegre/RS; após isso, fomos remanejados para Centro Municipal de Educação de Trabalhadores - CMET - Paulo Freire, também em Porto Alegre/RS, no $1^{\circ}$ e $2^{\circ}$ semestres de 2019, onde nos deparamos com o desafio encantador da EJA. Em ambas as escolas realizamos diagnósticos, percepções e observações para serem discutidas no grupo, a fim de conhecermos a realidade das comunidades escolares. Assim, conforme traçado no projeto, que buscava promover a inclusão social a partir da mobilização de uma comunidade específica - a comunidade escolar-, propusemos no CMET Paulo Freire os projetos: 1) Oficina "Na trilha dos Multiletramentos - Ciclo Jornal e Fotografia", que resultou na produção de um jornal escolar o qual ressignificasse a perspectiva de vida dos alunos; e, 2) Vivência "Na trilha dos Multiletramentos - Ciclo Cinema e Documentário", a qual os alunos-autores do documentário puderam (re)ver seus percursos de aprendizado, percebendo a escola como espaço de inclusão e transform(ação), de (re)pensar e (re)construir.

Deste modo, ao nos colocarmos em constante processo de (des)construção de conceitos, a fim de valorizarmos os conhecimentos prévios de nossos alunos e fazermos o possível para contextualizar a realidade deles, conseguimos com que os projetos interagissem com as disciplinas do currículo formal - adotado pela EMEF Timbaúva - e do 
currículo permanente ao longo da vida ${ }^{6}$ adotado pelo CMET Paulo Freire, superando a fragmentação do ensino, tranversalizando temas de diversas áreas do conhecimento e objetivando a formação integral dos alunos. A partir da pedagogia de projetos possibilitaram-se, tanto momentos de profunda felicidade por vê-los alçarem voo - mesmo que tardiamente, tal qual a ave de Minerva7 -, quanto o entusiasmo votivo ${ }^{8}$ do magistério, que nos impulsiona a manter sempre acesas as chamas da educação freireana, cujo princípio básico é a leitura do mundo e as experiências dos educandos, buscando alfabetizá-los a partir de suas realidades de vida.

\section{Desenvolvimento}

De acordo com o artigo $1^{\circ}$, parágrafo $2^{\circ}$ da Lei de Diretrizes e Bases da Educação Nacional - LDB 9394/96, a educação escolar deverá vincular-se ao mundo do trabalho e à prática social. Neste sentido, atualmente, fala-se muito na formação de indivíduos que sejam capazes de atuarem na sociedade de modo participativo, crítico, reflexivo, autônomo e solidário. Assim, a pedagogia de projetos, quando utilizada nas escolas, provoca nos alunos a busca por essas capacidades e outras necessárias a sua formação, tanto escolar (de maneira que o indivíduo se prepare para a vida futura) como social (visando ao momento presente).

É notório que o exercício da docência tem sua preocupação focada na formação básica dos educandos, ou seja, proficiência em leitura, na escrita, na interpretação, na realização de operações matemáticas e em outras áreas do conhecimento, assim, tão somente visando à vida profissional. Neste sentido, John Dewey (apud Libâneo, 1995), destacado educador norte-americano e personagem importante para a compreensão da educação contemporânea, contrapõe este raciocínio inferindo que a prática docente também deveria focalizar seus olhares para a formação axiológica (os valores morais e éticos da sociedade), intrínseca a nossa constituição como humanos que buscam a completude.

\footnotetext{
${ }^{6}$ Conforme o Projeto Político Pedagógico do CMET Paulo Freire, o currículo da escola recebe a denominação de Educação Permanente ao Longo da Vida, a qual contempla os princípios e a estrutura da EJA. Organiza-se por totalidades do conhecimento, fundamentais na construção de conceitos, na educação inclusiva, "na avaliação emancipatória e em cursos e oficinas periódicas indo além dos muros da escolarização" (MATOS; PEREIRA, 2019).

7 O filósofo alemão Friedrich Hegel (1770-1830) escreve em sua obra Princípios da Filosofia do Direito: "A ave de Minerva alça seu voo somente com o início do crepúsculo". Nesse sentido, entendemos que o papel do professor é justamente construir mecanismos pedagógicos (projetos) que auxiliem os alunos a perceber o que não é claro ao senso comum; a produção de alertas pedagógicos acerca da vida. $\mathrm{O}$ crepúsculo ou entardecer é o linear do dia para coruja - ave de Minerva-, pois, enquanto as demais aves cessam seus labores e se recolhem aos seus ninhos, a coruja "alça seu voo" em direção ao trabalho. O aluno da EJA, metaforicamente, torna-se um noctua, do latim "ave da noite", porquanto sua busca por uma visão completa que abarque todos os ângulos da realidade, que o capacite de ver o todo, não cessa nem diante da idade tardia do aprendizado (HEGEL, 1997).
}

${ }^{8}$ Adjetivo designativo "do voto" ou relativo a ele; um oferecimento em cumprimento de voto firmado. 
Dessa maneira, os projetos que detalharemos a seguir foram planejados de modo que contribuíssem para a educação, indo ao encontro das exigências da sociedade contemporânea. Assim, os olhares se voltam para um processo de construção participativa e focada em valores humanos, na dignidade, na solidariedade, no respeito e na tolerância mútua, características tão necessárias à formação dos cidadãos.

Nome do projeto: Oficina: Contadores de Histórias - Conte-me um conto.

Período: $2^{\circ}$ semestre de 2018

Local: Escola Municipal de Ensino Fundamental Timbaúva/Porto Alegre

Público: alunos dos $5^{\circ}, 6^{\circ}$ e $7^{\circ}$ anos do $\mathrm{EF}$, com idade entre 14 e 17 anos, que participavam do Laboratório Pedagógico de Língua Portuguesa da escola.

Contextualização/problematização: De acordo com Dell'isola (2007), para que os alunos possam saber manusear as habilidades de ler, escrever, ouvir e falar, objetivando utilizar a linguagem falada ou escrita na produção de novos textos, eles devem se defrontar tanto com o processo de textualização quanto com o de oralidade. Desse modo, provoca-se uma ruptura do tradicional - a prática existente na escola - com a identificação de tipos textuais que efetivamente constituem o texto.

Dos Santos et al. (2019) inferem que, com o intuito de sensibilizar os alunos a respeito de temas que são tão casuais - o descaso público e familiar com a educação, por exemplo -, a escolha de um conto contemporâneo possibilitaria conduzir os alunos à reflexão sobre a identidade do sujeito envolvido, dos sujeitos subjetivos e de suas próprias identidades diante das "casualidades" verossímeis. Assim, com a utilização da ludicidade de contar histórias e ouvi-las a partir do local onde está inserido, ele poderia acessar uma nova realidade proposta e repensar a própria realidade por meio da escrita.

A oficina consistiu na (re)textualização - processo de transformação de uma modalidade textual em outra - de um gênero conto em um gênero roteiro, composto de cenas-curtas que foram escritas pelos próprios alunos, os quais participam do laboratório pedagógico do educandário, a fim de melhorar a proficiência na disciplina de Língua Portuguesa. Foram realizados exercícios de letramento linguístico, baseados nos gêneros textuais, a partir de sequências pedagógicas fundamentadas em variações linguísticas tão importantes às vivências dos alunos, possibilitando a reflexão linguística deles.

Desenvolvimento/aplicação: a oficina de (re)textualização foi realizada em cinco módulos de duas horas e meia. Trabalhamos com um grupo de seis membros, e distribuímos o conto no primeiro dia para que pudéssemos contextualizá-lo. Após isso, solicitamos que eles realizassem uma leitura prévia, pois já sabiam antecipadamente o que fariam a partir do conto recebido, ou seja, roteiros e cenas.

Na primeira oficina fizemos uma parte expositiva, a partir da leitura do conto selecionado "Conte-me um Conto", com a compreensão textual do texto, suas características textuais, e a identificação do gênero por meio da leitura e compreensão dele. Nesse sentido, começamos a explicar os pressupostos da proposta: a) (re)textualização: realizar a escrita de um texto com as mesmas características do anterior, 
transformando-o em um gênero textual - roteiro de teatro; b) conferência: observar as condições de produção do gênero textual original e a manutenção das características presentes ou parte delas ao texto a ser produzido; c) identificação - verificação das características que compõem o texto original no texto produto da (re)textualização; d) reescrita: a versão final do texto produzido e os consequentes ajustes a serem realizados. Desta maneira, foram apresentados alguns modelos de roteiros de teatro escritos com cenas curtas, dos quais os alunos receberam explicações acerca da tessitura textual deles.

Por fim, nas três oficinas seguintes, os alunos discutiram o referido conto e começaram a construir um roteiro, de acordo com a dinâmica narrativa do conto proposto. Assim, na última oficina foram distribuídas as tarefas de acordo com o que o texto nos orientava (fala dos personagens, composição de cena, sonoplastia, figurinos e luzes) e com algumas adequações que o grupo livremente fazia, entretanto, sempre orientados quanto à identidade do texto e seu processo autoral diante do reconhecimento do texto lido.

\footnotetext{
Nome do projeto: Oficina: "Na trilha dos multiletramentos - ciclo jornal e fotografia conectando pessoas"
}

Período: $1^{\circ}$ semestre de 2019

Local: CMET Paulo Freire/Porto Alegre/RS

Público: alunos das totalidades iniciais e finais, correspondentes aos $6^{\circ}, 7^{\circ}$ e $8^{\circ}$ anos do EF com idade entre 16 e 24 anos que participam das oficinas pedagógicas da escola.

Contextualização/problematização: A oficina intitulada como "Jornal e Fotografia Conectando Pessoas" teve como objetivo realizar a inclusão social dos alunos a partir da comunidade escolar, tirando-os da passividade e tornando-os sujeitos ativos. Nesse sentido, foi realizado um processo de ressignificação, visto que os alunos se sentiam frustrados por ainda não terem concluído seus estudos e, muitas vezes, não se viam como protagonistas de suas próprias histórias.

Compreender a EJA, suas faces políticas e sociais, possibilitou-nos vislumbrar a importância do desenvolvimento da autoestima e do desejo dos sentimentos de pertencimento e de identidade dos alunos à escola, o que lhes facilitou a compreensão dos conteúdos apresentados na oficina, à medida que ambos - alunos e oficina - cresciam com a troca de saberes. Ter vontade de ir à escola e permanecer nela não somente pelo aprendizado, mas também por uma proposta que os envolvessem, eram os desafios que encontraríamos à frente para cativar os educandos.

Nesse contexto, defrontar-se com uma realidade educacional não envolvente e ter coragem para modificá-la exige a desconstrução de práticas pedagógico-didáticas canônicas, buscando diferentes alternativas que dialoguem com a diversidade cultural existente naquele espaço escolar. Assim, construindo e desconstruindo conceitos, convertendo o sensível ao inteligível por meio de um dialogismo baseado naquilo que se diz e porque se diz, a oficina oportunizada pelo subprojeto entrelaçou as trilhas dos bolsistas ID e oficinistas EJA, sujeitos protagonistas de histórias que se conectavam. 
- Revista de Iniciação à Docência, v. 5, n. 2, 2020 -

Publicação: agosto, 2020 - ISSN 2525-4332

Desenvolvimento/aplicação: As aulas foram desenvolvidas em sete encontros conforme o planejamento, ocorrendo às sextas-feiras à noite, tendo duas horas de duração cada. Para que a criação do jornal fosse possível, foi necessário contextualizar esse ambiente, por meio de manuseio dos jornais, leituras e seminários. A cada aula trabalhamos todos os aspectos que possibilitariam a construção de um jornal. As atividades realizadas foram monitoradas pelos bolsistas ID, os quais acompanhavam os alunos na correção e reescrita dos textos, observados os requisitos de coesão e coerência textual. De acordo com a proposta de desenvolvimento das atividades, foi respeitada a criatividade e a autoralidade ${ }^{9}$, tornando-os agentes ativos na construção de suas atividades, bem como, colocando-os como peças principais para o desenvolvimento e construção das aulas.

Na primeira aula, entregamos jornais para que eles pudessem observar e destacar os aspectos que chamaram suas atenções. Em seguida, foram apresentados slides com explicações acerca dos diferentes gêneros encontrados no jornal. Após esse momento, eles criaram manchetes a partir de fotos expostas nos slides, o que lhes possibilitou imergirem na criatividade, culminado na leitura do material produzido e resultando na elevação de suas autoestimas pela relevância do simples - porém, naquele espaço, potencializado pelo seu significado libertador - ato de leitura.

Na segunda aula, apresentamos as linguagens utilizadas no jornal, focando no gênero notícia, como: manchete ou título, título auxiliar, lide ${ }^{10}$ e corpo. Como atividade, sugerimos que os alunos escrevessem manchetes usando o lide a partir de fotos de acontecimentos expostos nos slides.

Na terceira aula, introduzimos o gênero reportagem e explicamos o que o constitui e qual sua utilidade. Foi sugerido como atividade que os alunos criassem perguntas para entrevistar alunos e professores em diferentes oficinas que estavam sendo ofertadas no CMET. Para isso, os alunos criaram 10 perguntas para os professores e 10 perguntas para os demais colegas do CMET Paulo Freire. Eles foram divididos em três grandes grupos, nos quais cada aluno ficava responsável por uma função, sendo elas: fotografia, entrevistador para professor, entrevistador para aluno, gravação e/ou anotação das respostas e demais curiosidades encontradas. Cada grupo entrevistou pessoas em duas oficinas, sendo que o resultado da coleta foi compartilhado após todo o processo.

Na quarta e na quinta aula foram corrigidas as entrevistas e, a partir delas, os alunos começaram a redigir as reportagens focando atenção na elaboração do lide, de acordo com a estrutura da narrativa da reportagem. Foram disponibilizados três notebooks para que os

\footnotetext{
${ }^{9}$ De acordo com Dominique Maingueneau (1950), a autoralidade, conforme a Análise do Discurso é um campo de saber que estuda a sobreposição recíproca de textos e de lugares sociais dos sujeitos, suas fronteiras e cruzamentos, seus textos e contextos (MAINGUENEAU, 2001).

10 Termo aportuguesado do inglês que significa liderar, conduzir o qual é utilizado pelo jornalismo para resumir a função do primeiro parágrafo, de modo a introduzir o leitor no texto, assim, prendendo a atenção dele. Na oficina, trabalhou-se com um tipo básico do lide denominado "noticioso", que responde às questões inerentes de um fato (o quê, quem, quando, como, onde, por quê).
} 
alunos pudessem produzir as reportagens, momento em que cada componente do grupo sugeriu ideias de edição, de diagramação e de fotos a serem utilizadas.

Por fim, nas sexta e sétima aulas, para criação e diagramação do produto final, trabalhou-se a escolha de fonte, o nome do jornal, o título das matérias e quais as atividades disponibilizadas pelo CMET Paulo Freire ${ }^{11}$, frutos de parcerias ${ }^{12}$ firmadas com universidades e entidades governamentais, seriam publicadas no jornal. Assim, com muito trabalho e dedicação, o “CMET Jornal”, contendo 11 páginas foi publicado, iniciando seu conteúdo com a matéria sobre a história do CMET, seguida das reportagens e criações dos alunos as quais foram realizadas durante as aulas do projeto. $O$ jornal foi lançado no final do $1^{\circ}$ semestre de 2019, com a presença de todos os oficinistas, no evento de formatura da escola. vivências"

Nome do projeto: Oficina: "Na trilha dos multiletramentos - ciclo cinema - ressignificando

Período: $2^{\circ}$ semestre de 2019

Local: CMET Paulo Freire/Porto Alegre

Público: alunos das totalidades finais, correspondentes aos $8^{\circ}$ e $9^{\circ}$ anos do EF com idade entre 16 e 74 anos que participam das vivências pedagógicas da escola.

Contextualização/problematização: As políticas de educação no Brasil em um recorte histórico apontaram indícios nos quais as desigualdades sociais foram fortalecidas para a manutenção de uma classe elitizada e a exclusão da classe trabalhadora, de baixa renda, o que ampliava a distância das oportunidades de acesso destes sujeitos a uma educação de qualidade. Nesse contexto, quanto maior era distância operacionalizada na educação por meio de um conjunto de desigualdades sociais constituído pela miséria, injustiça, exploração social e econômica, marginalização social, entre outras significações, menor era o número daqueles que conseguiam sair do processo excludente e conquistar sua alfabetização.

As possibilidades de ressignificação dos alunos da EJA se dão por meio das experiências que constituem caminhos de valorização e aproximação de espaços vividos e sentidos por eles. Logo, este projeto tem seu marco inicial a partir da proposta de vivências culturais as quais se apresentam como alternativa transversal ao "currículo da vida" implementado no CMET.

É importante destacar que a EJA se constitui num espaço especial de

\footnotetext{
${ }^{11}$ Experiências únicas e variadas que concebem novas formas de ensinar e aprender, de acordo com os interesses e necessidades dos alunos, entre as quais podemos citar algumas: "RadioWeb", "Viver Bem em Todas as Idades", "Leitura Além do Texto", "Plantas Medicinais e Artes", “Arte Urbana: Pintura Mural”, "Vivência em Matemática", "Prática de Bandas".

${ }^{12}$ O CMET tem parcerias com a UERGS e UFRGS, possibilitando estágios curriculares, assim como, ofertas de oficinas aos alunos nas sextas-feiras. Além disso, o CMET mantém duas extensões: a Cooperativa CrêSer e o Projeto Compartilhar (coordenação conjunta com o DMAE e DMLU, que oportuniza a escolarização dos funcionários municipais, tanto no Ensino Fundamental, como no Ensino Médio). Desde o ano de 2018, o CMET Paulo Freire tornou-se parceiro do Ministério Público da Infância e da Juventude com um projeto financiado pela Organização Internacional do Trabalho implementando cursos profissionalizantes ministrados por professores do SENAC (Serviço Nacional do Comércio), direcionados, principalmente, aos alunos em situação de risco e abrigados.
} 
representações diferenciadas da sociedade, pois na sala de aula estão presentes as diversas manifestações das práticas relacionadas às vivências socioculturais. Neste contexto multicultural em que há o (des)encontro de faixas etárias tão diferentes, também se reflete a necessidade de uma reorganização pedagógica e a possibilidade de que novas práticas que acolham e envolvam o público jovem e adulto sejam construídas para alcançar o aprendizado. Logo, é necessário compreender que a EJA é espaço formativo em que as condições de produção do processo dialógico de lutas devem ser revitalizadas diariamente, pois a educação para os sujeitos da EJA não ocorre por dádiva, mas pelas suas conquistas.

Desenvolvimento/aplicação: Freire (2003) assinala que os oprimidos se adaptam à condição de não liberdade e acabam por se acostumar em permanecer em meridianos de distância - sociais e culturais -, impostos, principalmente, pela escola. De acordo com o referido educador, os alunos da EJA são o que hoje podemos definir como os oprimidos e o sistema (o aparato social, político, estatal e econômico) como opressor. Desta maneira, produzir um documentário como opção metodológica que buscasse dar voz aos alunos da EJA se constituiu em (re)construir memórias e (res)significações de subjetividades deles.

Durante a realização dessa vivência, optou-se por contextualizar o gênero documentário abordando o passo a passo mais comum a essa modalidade cinematográfica, a saber: a) pesquisa: avaliação da aplicabilidade da ideia do documentário (a profundidade do tema, lugar das filmagens, material em arquivo); b) planejamento: organização dos elementos técnicos e burocráticos (materiais e uso de imagem); c) argumento: o que o documentário quer contar, sua relevância; d) roteiro: ordem das filmagens e especificações sobre a abordagem a ser realizada; e) filmagem: o que foi planejado e o que surgirá no improviso; f) som: som direto e sons produzidos (trilhas e efeitos) e edição (estruturação da narrativa pretendida, do material bruto ao refinado). Dessa maneira, a cada encontro uma etapa era executada e concluída, de modo que os alunos fossem criando uma tessitura memorial do CMET.

\section{Resultados e Discussão}

\section{Oficina: contadores de histórias - conte-me um conto.}

Foi um trabalho que desafiou os discentes em uma leitura a qual demandou a seleção e construção de critérios importantes para o recorte de trechos do conto, a fim de elaborarem um roteiro. Isso fomentou a discussão entre os sujeitos participantes da oficina, momento em que cada um trouxe sua colaboração sobre os diálogos (cômico, emotivo, decisivo, entre outros) para a sala de aula, auxiliando na seleção das falas.

Os alunos não tiveram só a oportunidade de discutir o conto, mas também de usar a criatividade para estruturar diferentes modos de adaptar o conto ao roteiro. Acompanhamos todo o processo de elaboração do roteiro e pudemos perceber que a transposição do texto escrito (roteiro) em elementos orais (falas) se constituiu em um desafio, porque eles teriam de organizar as marcações de espaço e condições de contexto. 
Destaca-se também como dificuldade transposta pelos alunos, a adaptação do papel do narrador onisciente em $3^{\text {a }}$ pessoa do conto para o roteiro. Os alunos, ao realizarem a troca do gênero textual, tiveram que configurar os elementos encontrados no conto - alegria, tristeza, medo, surpresa, entre outros - para o palco por meio de som e luzes, criando assim, efeitos de sentido para cada emoção ou antecipação delas por prolepse. Além disso, as marcas de identificação do discurso direto e indireto, que não são tão óbvias no conto, ficaram no roteiro criando o tônus do gênero. Enfim, antes de as cortinas se abrirem para a apresentação da dramatização do conto retextualizado no evento de encerramento das atividades do $2^{\circ}$ semestre de 2018 do subprojeto, no campus universitário da Uergs, os alunos-atores explicaram, de modo sucinto, como ocorreu todo o processo de criação até chegada ao produto final, diante de uma plateia repleta dos demais participantes oficinas do subprojeto Letras: Língua Portuguesa/Uergs.

\section{Oficina: "Na trilha dos multiletramentos - ciclo jornal e fotografia - conectando pessoas"}

Após a realização das atividades, foi possível perceber a construção da identidade, não só dos alunos, como também da escola, pois eles puderam explorar o espaço escolar e suas variáveis de espaço, tais como: as atividades ofertadas por outros professores, o convívio com diferentes idades e pensamentos, visões e sonhos. Os alunos intensificaram suas habilidades orais e escritas, visto que passaram a questionar suas posturas em diferentes situações, bem como a exercitar a escuta em suas interações com outros colegas e professores.

Desse modo, a construção do jornal trouxe a valorização de si mesmo como aluno, sendo aquele que tem capacidade de construção da sua identidade, do que pretendem ser e assumir sua responsabilidade de ser protagonista e ter um local de fala. Assim sendo, além do jornal propriamente dito, o produto culminou também na cumplicidade, no respeito e na união de grupo, portanto, atitudes construídas durante as aulas.

\section{Oficina: "Na trilha dos multiletramentos - ciclo cinema - ressignificando vivências"}

O documentário discorre, em momentos bem distintos, sobre as vivências dos alunos na busca de ressignificação social e traz o que eles têm a dizer sobre a experiência de retorno à escola, o abandono desta e seus porquês, as experiências de vida e os entraves dela numa sociedade nada inclusiva. Desse modo, a partir de uma narrativa em $1^{\mathrm{a}}$ pessoa os alunos tornaram-se autores de suas histórias, mobilizando discursos tensionados na negociação de significados, mergulhando em uma arena intercultural e problematizando, com suas experiências, o binômio: inclusão ("uma conquista") e exclusão ("nem dádiva nem presente").

Logo, ressignificar os espaços e reconhecer os discursos - os outros que falam na memória da escola - foram aspectos considerados no direcionamento da vivência durante a produção do material em mídia. Sendo assim, a luta que o CMET realiza pela construção do sujeito oprimido e tangenciado das oportunidades foi sendo tecida e espaços de fala foram dados àqueles que estão do outro lado da linha imaginária criada pela sociedade, e 
- Revista de Iniciação à Docência, v. 5, n. 2, 2020 -

Publicação: agosto, 2020 - ISSN 2525-4332

que ali, no espaço escolar, receberam o direito à fala.

\section{Considerações finais}

Segundo Paulo Freire (1996), o binômio ensinar e aprender necessita do esforço metódico e crítico do professor e do aluno. O primeiro atuando como sujeito do desvelamento da compreensão de algo e a deflagrando - não transferindo - ao segundo, que atuará como sujeito na aprendizagem, assim, gerando, nas palavras do educador, a "boniteza da docência e da discência" (p. 119).

Nesse sentido, os estudantes - EF ou EJA - que participaram das oficinas e vivências estão inseridos em contextos sociais em que a informação - sua difusão e recepção, embora os aproxime, também os afasta - processa-se e evolui de maneira célere. Para que eles possam acompanhar tal evolução e não fiquem a margem dela, faz-se necessário uma revolução copernicana na educação que rompa com os obstáculos da desinformação, do isolamento e da liquidez do contexto da realidade.

Morin (2014) mostra que o conhecimento, para ser significativo e ter sentido, necessita que as informações e os dados sejam contextualizados e relacionados aos novos conhecimentos os quais se adquirem e aos que os alunos já possuem. Deste modo, os trabalhos propostos e desenvolvidos nas escolas buscaram transversalizar os conhecimentos, aguçando a percepção dos alunos ao novo que seria apresentado e ao já adquirido o qual seria valorizado.

Nesse contexto, ao analisarmos a retextualização do conto, percebemos que os alunos fizeram as escolhas de partes fundamentais da narrativa, objeto da oficina, e de maneiras apropriadas de textualizar. Estas escolhas envolveram a apropriação de conteúdos de reflexão linguística que os conduziram ao melhor modo de produzir um texto coerente, coeso e relacionado às situações de uso. Assim, não se pode ignorar o fato de que os alunos já conheciam o que é um conto e, com o exercício da dramatização - ora, somos todos, em algum momento de nossas vidas, atores de um teatro real -, eles puderam mexer com a imaginação e provocar o conhecimento prévio.

E quanto à oficina de multiletramentos - ciclo jornal e fotografia, a diversidade de pensamentos existentes na sala de aula abriu espaço ao respeito à exposição de opiniões e de posicionamentos críticos. Na troca de experiências realizadas em sala, aprendemos muito mais do que ensinamos, cada qual com seu insumo, fomentando e discutindo, criando e ressignificando. Assim, a produção do "CMET Jornal” propiciou o trabalho com o letramento dos educandos na atividade de escrita e reescrita, pré-leitura, leitura e pósleitura de textos por eles mesmos produzidos, portanto, dando um novo sentido à produção textual, tornando o ensino e a aprendizagem mais dinâmicos e participativos.

E naquele mesmo espaço da EJA, com a elaboração do documentário, os alunos propuseram novas histórias para velhas histórias, respeitando erros e acertos, e mostrando que mudanças só ocorrem quando se deseja intensamente ser protagonista de sua história. 
Portanto, ao compreender as relações desveladas que constituíram a vivência pedagógica, no cruzamento bilateral dos discursos que as instituíram - em lugar e posição - permitiramnos analisar o funcionamento das práticas escolares no contexto da EJA.

Desta maneira, o Pibid, como construto de formação de futuros professores, tornase motor na promoção de mecanismos alternativos à apropriação de práticas didáticopedagógicas que visam à emancipação e o crescimento individual e coletivo. Assim, a partir da imersão no contexto da realidade escolar propiciada pelo projeto, nós, bolsistas iniciação à docência experienciamos momentos de intensas vivências pedagógicas que, certamente, contribuirão para a nossa formação enquanto alunos da graduação e, no futuro, como professores de Língua Portuguesa.

\section{Referências}

BAZERMAN, C. Escrevendo Bem, Científica e Retoricamente: consequências práticas para escritores da ciência e seus professores. Ch. Bazerman, Gênero, Agência e Escrita. São Paulo/SP: Cortez, 2006, p. 59-77.

BRASIL. Coordenação de Aperfeiçoamento de Pessoal de Nível Superior. Portaria GAB n. 45, de 12 de março de 2018. Dispõe sobre a concessão de bolsas e o regime de colaboração no Programa de Residência Pedagógica e no Programa Institucional de Bolsa de Iniciação à Docência. Brasília/DF: CAPES, 2018. Disponível em:

https://www1.capes.gov.br/images/stories/download/legislacao/16032018_Portaria_45_Regulamento_PIBID_e_Residencia_ Pedagogica_SITE.pdf. Acesso em 30 set. 2019.

BRASIL, L. D. B. Lei 9.394/96. Diretrizes e Bases da Educação Nacional. Brasília/DF: MEC, 1996.

CAVALCANTE, M. Interdisciplinaridade: um avanço na educação. Nova Escola, 2004, p. 5255 .

DELL'ISOLA, R. L. P. Retextualização de gêneros escritos. Rio de Janeiro/RJ: Lucerna, 2007.

DOS SANTOS, M. S. et al. Retextualização em sala de aula: da leitura de um conto à criação de um roteiro, uma experi (viv)ência pibid. In: IX SIEPEX-IX Salão Integrado de Ensino, Pesquisa e Extensão, 2019.

DUSSEL, E. Filosofia da libertação: crítica à ideologia da exclusão. São Paulo/SP: Paulus, 2005.

FAZENDA, I. C. A.; CASADEI, S. R. Natureza e Interdisciplinaridade: reflexões para a Educação Básica. Interdisciplinaridade. Revista do Grupo de Estudos e Pesquisa em Interdisciplinaridade, n. 2, 2012, p. 43-71.

FREIRE, P. Educação de adultos: algumas reflexões. In: GADOTTI, M.; ROMÃO, J. E. (Orgs). Educação de jovens e adultos: teoria, prática e proposta. São Paulo/SP: Cortez; Instituto Paulo Freire, 2003.

. Pedagogia da autonomia: saberesnecessários à pratica educativa.

$29^{\circ}$ edição. São Paulo/SP. Paz e Terra, 1996.

GRASSI, A. C. et al. CMET Paulo Freire: 30 anos de vidas. Revista CMET Paulo Freire: 30 anos de educação, n. 1, 2019, p. 6-7. 
- Revista de Iniciação à Docência, v. 5, n. 2, 2020 -

Publicação: agosto, 2020 - ISSN 2525-4332

HEGEL, G. W. F. Princípios da filosofia do Direito. 1997.

LEAL, R. B. Planejamento de ensino: peculiaridades significativas. Revista Iberoamericana de Educación, v. 37, n. 3, 2005, p. 1-6.

LIBÂNEO, J. C. Tendências pedagógicas na prática escolar. In LIBÂNEO, J. C.

Democratização da Escola pública: a pedagogia crítico-social dos conteúdos. São Paulo/SP: Edições Loyola, 1995, p. 19-44.

MATTOS, P. A. P.; PEREIRA, R. S.R. Por uma poética dos saberes. Revista CMET Paulo Freire: 30 anos de educação, n. 1, 2019, p. 8-10.

MAINGUENEAU, D. Análise de textos de comunicação. São Paulo/SP: Cortez, 2001.

MOREIRA, M. A. Teorias de aprendizagem. São Paulo/SP: EPU, 1999.

MORIN, E. et al. Os setes saberes necessários à educação do futuro. São Paulo/SP: Cortez Editora, 2014.

RINCK, F.; MANSOUR, L. Letramento na era digital: o copiar-colar dos estudantes. Raído, v. 8, n. 16, 2014, p. 15-32. 